08.2

\title{
Вертикальное упорядочение аморфных нанокластеров Ge в многослойных гетероструктурах $a$-Ge/a-Si:H
}

\author{
(C) Г.Н. Камаев ${ }^{1}$, В.А. Володин ${ }^{1,2}$, Г.К. Кривякин ${ }^{1,2}$ \\ ${ }^{1}$ Институт фризики полупроводников им. А.В. Ржанова СО РАН, Новосибирск, Россия \\ ${ }^{2}$ Новосибирский государственный университет, Новосибирск, Россия \\ E-mail: kamaev@isp.nsc.ru
}

Поступило в Редакцию 8 февраля 2021 г.

В окончательной редакции 11 марта 2021 г.

Принято к публикации 17 марта 2021 г.

\begin{abstract}
Исследована многослойная гетеронаноструктура, состоящая из трех пар слоев аморфного кремния и аморфного германия ( $a-\mathrm{Ge} / a-\mathrm{Si}: \mathrm{H})$, выращенная на подложке кремния методом низкочастотного плазмохимического осаждения при температуре $225^{\circ} \mathrm{C}$. На основе анализа спектров комбинационного рассеяния света определен фазовый состав слоев кремния и германия, который показал, что слои полностью аморфны. На изображениях, полученных с помощью просвечивающей электронной микроскопии, наблюдаются упорядоченные в вертикальном направлении аморфные нанокластеры $\mathrm{Ge}$, формирование которых инициировано локальными неоднородностями нанометрового масштаба в первом слое германия, латеральные размеры которых растут от нижнего слоя к верхнему.
\end{abstract}

Ключевые слова: германий, кремний, гетерограница, самоорганизация, нанокластер.

DOI: 10.21883/PJTF.2021.12.51060.18728

Гетероструктуры Ge/Si, а также многослойные наноструктуры, состоящие из включений германия, внедренных в более широкозонный кремний, вызывают как фундаментальный, так и прикладной интерес [1-3]. Гетероструктуры с квантовыми точками германия в кремниевой матрице, встроенные в различные резонаторы, позволяют достигать квантовой эффективности, достаточной для использования в кремниевой оптоэлектронике [4]. Эпитаксиальные гетероструктуры $\mathrm{SiGe} / \mathrm{Si}(001)$ рассматриваются как один из вариантов неоксидных мемристоров с филаментарным механизмом проводимости, в которых прорастающие дислокации в эпитаксиальном слое твердого раствора $\mathrm{SiGe}$ выступают в качестве проводящих каналов [5]. Внедрение наночастиц германия и олова в нелегированный слой $p-i-n$-структур на основе пленок аморфного и микрокристаллического кремния позволяют повысить КПД солнечных элементов [6-9] и расширить спектр поглощения в длинноволновой области для солнечных элементов и фотодиодов [10]. Для создания подобных структур на широкоформатных нетугоплавких подложках используются плазмохимические методы осаждения и последующие импульсные лазерные отжиги [11]. Известно, что различие постоянных решеток германия и кремния играет большую роль в механизмах самоорганизации наноструктур (квантовых точек) германия $[2,12,13]$. Настоящая работа является попыткой исследовать эффекты самоорганизации аморфных нанокластеров в многослойных гетероструктурах на основе аморфных гидрогенизированных слоев германия и кремния.

Многослойная гетеронаноструктура $a-\mathrm{Ge} / a-\mathrm{Si}: \mathrm{H}$, состоящая из трех пар слоев аморфного германия (по $15 \mathrm{~nm}$ ) и аморфного кремния (по $40 \mathrm{~nm}$ ), была выращена методом низкочастотного $(55 \mathrm{kHz})$ плазмохимического осаждения на подложке кремния с ориентацией (001) при температуре $225^{\circ} \mathrm{C}$. Рост слоев германия осуществлялся путем разложения германа $\left(\mathrm{GeH}_{4}\right)$, а рост слоев кремния - силана $\left(\mathrm{SiH}_{4}\right)$. Первый и последний слои - аморфный кремний. Более подробно условия роста приведены в работе [11].

Исследования проводились с применением спектроскопии комбинационного рассеяния света (КРС), инфракрасной фурье-спектроскопии поглощения (Fouriertransform infrared spectroscopy, FTIR), просвечивающей электронной микроскопии (Transmittance electron microscopy, TEM). Спектры КРС регистрировались в геометрии обратного рассеяния, в качестве источника возбуждения использовалась линия $\mathrm{Ar}^{+}$-лазера с длиной волны $514.5 \mathrm{~nm}$. Использовался спектрометр Т64000 (Horiba Jobin Yvon) в одинарной моде, спектральное разрешение было не хуже $2 \mathrm{~cm}^{-1}$. Чтобы избежать локального нагрева пленки, лазерный луч был расфокусирован, диаметр пятна составлял $20 \mu \mathrm{m}$, мощность излучения на поверхности образцов около $2 \mathrm{~mW}$. Анализ состояний водорода в слоях проведен на основании данных FTIR-спектроскопии, полученных на спектрометре ФТ-801 (ООО НПФ „СИМЕКС“, Новосибирск) со спектральным разрешением $4 \mathrm{~cm}^{-1}$. ТЕМ-изображения получены на микроскопе JEM-2200FS.

На рис. 1 приведен спектр КРС исходной многослойной гетеронаноструктуры $a$-Ge/a-Si:H. В спектре присутствует широкий пик с максимумом $\sim 480 \mathrm{~cm}^{-1}$, обусловленный максимумом плотности колебательных состояний в аморфном кремнии [14], так называемый 


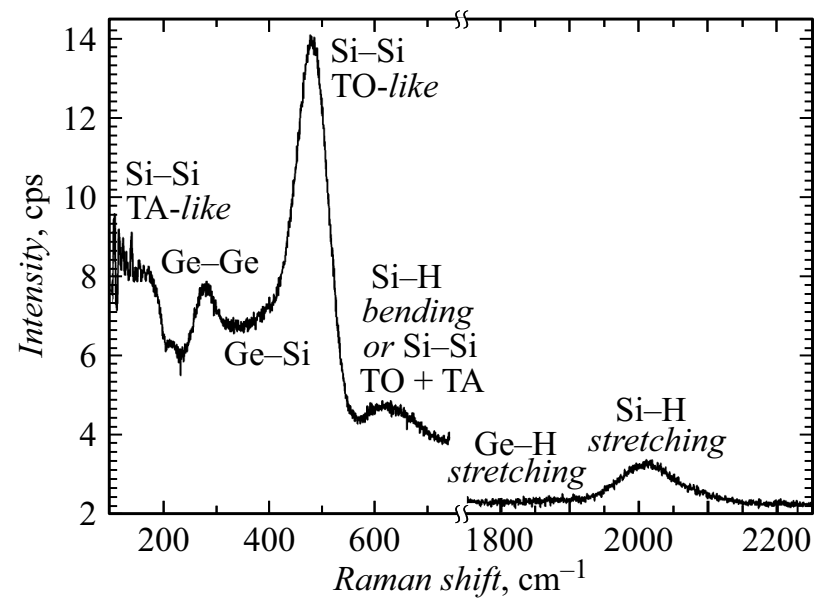

Pис. 1. Спектр комбинационного рассеяния света многослойной гетеронаноструктуры $a-\mathrm{Ge} / a$-Si:H.

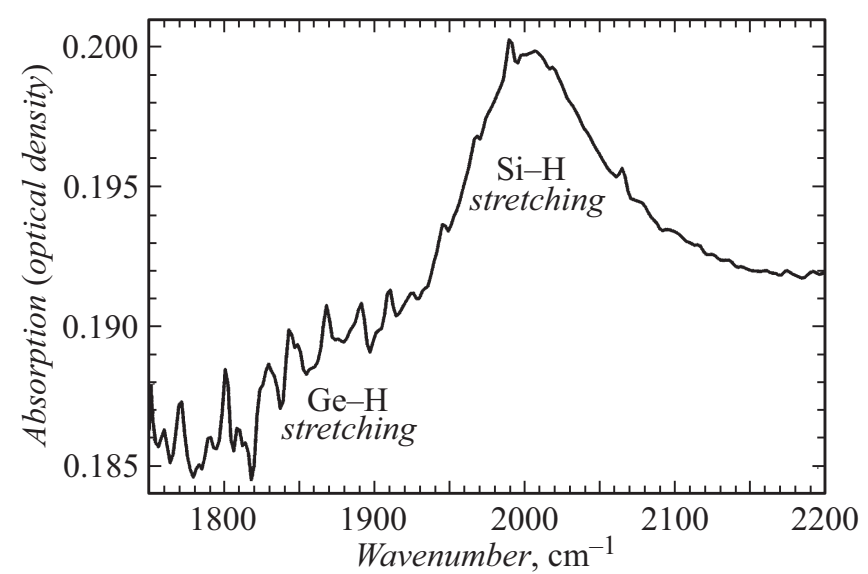

Puc. 2. FTIR-спектр многослойной гетеронаноструктуры $a-\mathrm{Ge} / a-\mathrm{Si}: \mathrm{H}$.

ТО-пик, образованный колебаниями типа поперечных оптических мод - transverse optical (TO). Наблюдаемый широкий пик с максимумом $\sim 275 \mathrm{~cm}^{-1}$ связан с максимумом плотности колебательных состояний в аморфном германии [15]. Частоты колебаний связей германий-кремний составляют $\sim 400 \mathrm{~cm}^{-1}[16]$, однако особенностей в спектре с данной частотой практически не видно. По-видимому, концентрация таких связей мала, хотя они должны присутствовать на гетерограницах слоев германий-кремний. В районе $620 \mathrm{~cm}^{-1}$ проявляется слабый пик, который может быть обусловлен как двухфононным рассеянием на поперечных оптических и поперечных акустических модах (ТО + ТА), так и однофононным рассеянием на изгибных модах (bending) колебаний связей $\mathrm{Si}-\mathrm{H}$ [17]. В спектре КРС также присутствует пик от валентных (stretching) колебаний связей $\mathrm{Si}-\mathrm{H}[18]$.

Обратимся к валентным колебаниям связей $\mathrm{Si}-\mathrm{H}$ и $\mathrm{Ge}-\mathrm{H}$ в диапазоне частот $1800-2200 \mathrm{~cm}^{-1}$ (FTIR-спектры, рис. 2). Видно, что присутствует пик, соответствующий колебаниям связей $\mathrm{Si}-\mathrm{H}\left(2000 \mathrm{~cm}^{-1}\right)$, и слабое высокочастотное ,Плечо“, которое относится к колебаниям связей $\mathrm{Si}-\mathrm{H}_{2}\left(2100 \mathrm{~cm}^{-1}\right)$ [18]. Значит, водород в пленках содержится в основном в форме связей $\mathrm{Si}-\mathrm{H}$. Определенная исходя из отношения их интенсивностей к интенсивности пика $\mathrm{Si}-\mathrm{Si}$ в данной структуpe [19] концентрация водорода в слоях кремния составляет $\sim 20$ at.\%. Известно, что частота пика валентных колебаний связей $\mathrm{Ge}-\mathrm{H}$ составляет $\sim 1890 \mathrm{~cm}^{-1}$ [20]. Однако в этом диапазоне видна лишь небольшая особенность (на уровне шумов) в виде „плеча“. Это свидетельствует о том, что концентрация водорода в слоях германия не превышает 1-2 at.\%. Таким образом, данные FTIR (рис. 2) подтверждают данные КРС (рис. 1).

На рис. 3, $a, b$ приведены ТЕМ-изображения многослойной гетеронаноструктуры $a-\mathrm{Ge} / a-\mathrm{Si}: \mathrm{H}$ в различных масштабах. На рис. 3, $a$ с меньшим увеличением на фоне сплошных слоев наблюдаются нанокластеры, которые образованы в слоях германия. Обращает на себя внимание тот факт, что нанокластеры размещены в вертикальном направлении друг над другом, т.е. наблюдается их взаимное упорядочение в вертикальном направлении. Ярко выраженного упорядочения кластеров в слое в латеральной плоскости не наблюдается. Кластеры имеют разный диаметр. Наряду с крупными кластерами, отстоящими друг от друга на $\sim 250 \mathrm{~nm}$ (помечены на рисунке как 1 и 2), в слоях присутствуют более мелкие кластеры (помечены как 3 и 4). Однако можно обратить внимание на то, что диаметр кластеров увеличивается при переходе от нижнего слоя к верхнему. Так, если в нижнем слое внешний радиус изгиба кластера германия составляет $\sim 50 \mathrm{~nm}$, то в верхнем слое он достигает $\sim 100 \mathrm{~nm}$.

Первый осажденный слой кремния плоский, однородный по толщине. Второй и последующие слои кремния уже имеют разный рельеф и неоднородности в зависимости от размера кластеров германия. При этом они все накрывают имеющие куполообразную форму кластеры германия. Это ярко прослеживается на верхнем слое кремния (рис. $3, b$ ).

Известно, что у кристаллического германия постоянная решетки на $4.2 \%$ больше, чем у кристаллического кремния, и это играет большую роль в механизмах роста германия на кремнии $[2,12,13]$. Так, установлено, что на начальной стадии формирования пленки $\mathrm{Ge}$ возникают двумерные островки высотой не более $1 \mathrm{~nm}$. В квазиравновесных условиях роста островки разрастаются в латеральных направлениях, сохраняя постоянную высоту. При последующем росте на поверхности смачивающего слоя формируются пирамидальные островки, которые могут выступать в качестве напряженных затравок для управления пространственным расположением растущих нанокристаллов $\mathrm{Ge}$ с вертикальным совмещением в многослойных структурах $\mathrm{Ge} / \mathrm{Si}$. Наличие локальных неоднородностей в пленках аморфного кремния также приводит к формированию нановключений при осаждении германия [9]. В плоских слоях германия 

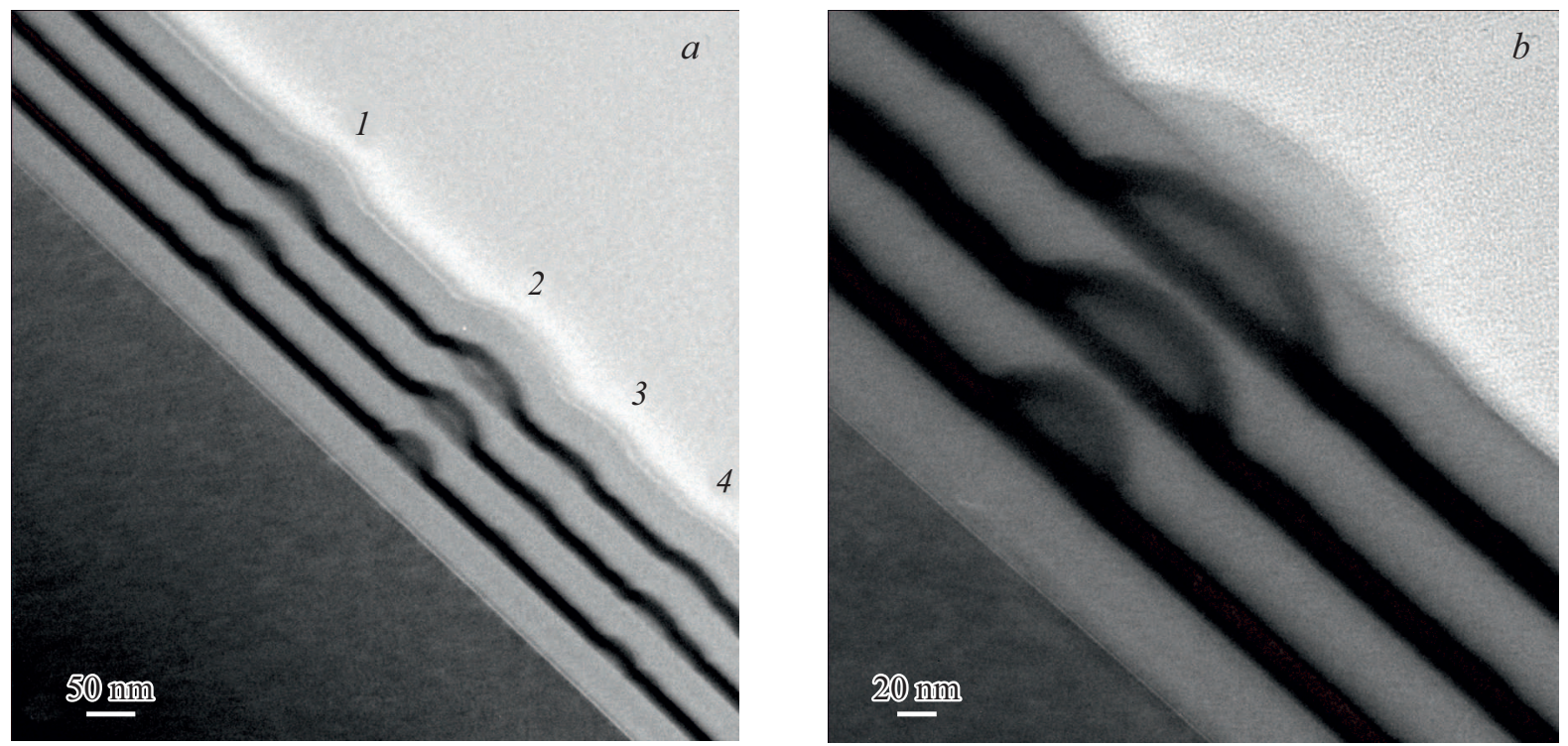

Рис. 3. ТЕМ-изображения многослойной гетеронаноструктуры $a$-Ge/a-Si:H.

могут присутствовать деформации сжатия, а в изогнутых слоях деформации неоднородны, при внешнем радиусе кривизны $50 \mathrm{~nm}$ и толщине слоя $15 \mathrm{~nm}$ (внутренний радиус $35 \mathrm{~nm}$ ) неоднородность такова, что внешний слой германия уже не сжат, а растянут. При росте слоя кремния на такой поверхности энергия деформации должна влиять на рост: в области растянутого германия осаждение кремния невыгодно, поэтому наблюдается некоторое выравнивание рельефа. Германию же, наоборот, более выгодно осаждаться на область растянутого кремния. Вероятно, это и является основным фактором для взаимного упорядочения кластеров в вертикальном направлении. Требуется дальнейшее изучение, направленное на вариацию толщины осаждаемых слоев, с целью исследования возможности формирования многослойных структур со встроенными нанокластерами $\mathrm{Ge}$ в аморфной матрице $\mathrm{Si}$ с взаимным вертикальным упорядочением.

\begin{tabular}{crr} 
В & многослойной & \multicolumn{2}{c}{ гетеронаноструктуре } \\
$a-\mathrm{Ge}(15 \mathrm{~nm}) / a-\mathrm{Si}: \mathrm{H}(40 \mathrm{~nm})$ & обнаружено взаимное
\end{tabular} вертикальное упорядочение в расположении аморфных нанокластеров германия, формирование которых инициировано наличием островков нанометрового масштаба в первом слое германия. В последующих слоях германия формируются кластеры, высота и латеральные размеры которых растут от нижнего слоя к верхнему.

\section{Благодарности}

Авторы выражают благодарность ЦКП „ВТАН“ НГУ за предоставление оборудования для регистрации спектров КРС и получения ТЕМ-изображений.

\section{Финансирование работы}

Исследования выполнены в рамках государственного задания Министерства образования и науки РФ (программа фундаментальных исследований ИФП СО РАН).

\section{Конфликт интересов}

Авторы заявляют, что у них нет конфликта интересов.

\section{Список литературы}

[1] J. Liu, R. Camacho-Aguilera, J.T. Bessette, X. Sun, X. Wang, Y. Cai, L.C. Kimerling, J. Michel, Thin Solid Films, 520, 3354 (2012). DOI: 10.1016/j.tsf.2011.10.121

[2] О.П. Пчеляков, Ю.Б. Болховитянов, А.В. Двуреченский, Л.В. Соколов, А.И. Никифоров, А.И. Якимов, Б. Фойхтлендер, ФТП, 34 (11), 1281 (2000). http://journals.ioffe.ru/articles/37278

[Пер. версия: 10.1134/1.1325416].

[3] E.G. Barbagiovanni, D.J. Lockwood, P.J. Simpson, L.V. Goncharova, Appl. Phys. Rev., 1, 011302 (2014). DOI: $10.1063 / 1.4835095$

[4] Ж.В. Смагина, А.В. Новиков, М.В. Степихова, В.А. Зиновьев, Е.Е. Родякина, А.В. Ненашев, С.М. Сергеев, А.В. Перетокин, П.А. Кучинская, М.В. Шалеев, С.А. Гусев, А.В. Двуреченский, ФТП, 54 (8), 708 (2020). DOI: $10.21883 /$ FTP.2020.08.49639.9392

[Пер. версия: 10.1134/S1063782620080230].

[5] О.Н. Горшков, В.Г. Шенгуров, С.А. Денисов, В.Ю. Чалков, И.Н. Антонов, А.В. Круглов, М.Е. Шенина, В.Е. Котомина, Д.О. Филатов, Д.А. Серов, Письма в ЖТФ, 46 (2), 44 (2020). DOI: 10.21883/PJTF.2020.02.48953.18075

[Пер. версия: 10.1134/S106378502001023X].

[6] Z. Liu, T. Zhou, L. Li, Y. Zuo, C. He, C. Li, C. Xue, B. Cheng, Q. Wang, Appl. Phys. Lett., 103, 082101 (2013). DOI: $10.1063 / 1.4818999$ 
[7] N.G. Galkin, K.N. Galkin, I.M. Chernev, R. Fajgar, T.H. Stuchlikova, Z. Remes, J. Stuchlik, Phys. Status Solidi C, 10, 1712 (2013). DOI: 10.1002/pssc.201300362

[8] Г.К. Кривякин, В.А. Володин, С.А. Кочубей, Г.Н. Камаев, A. Purkrt, Z. Remes, R. Fajgar, T.H. Stuchliková, J. Stuchlik, ФТП, 50 (7), 952 (2016).

http://journals.ioffe.ru/articles/43297

[Пер. версия: 10.1134/S1063782616070101].

[9] Г.К. Кривякин, В.А. Володин, А.А. Шкляев, V. Mortet, J. More-Chevalier, P. Ashcheulov, Z. Remes, T.H. Stuchliková, J. Stuchlik, ФTП, 51 (10), 1420 (2017). DOI: 10.21883/FTP.2017.10.45024.8547 [Пер. версия: 10.1134/S1063782617100128].

[10] C. Li, J. Ni, X. Sun, X. Wang, Z. Li, H. Cai, J. Li, J. Zhang, J. Phys. D: Appl. Phys., 50, 045108 (2017).

DOI: $10.1088 / 1361-6463 / a a 4 f 93$

[11] В.А. Володин, Г.К. Кривякин, Г.Д. Ивлев, С.Л. Прокопьев, С.В. Гусакова, А.А. Попов, ФТП, 53 (3), 423 (2019). DOI: 10.21883/FTP.2019.03.47298.8997 [Пер. версия: 10.1134/S1063782619030217].

[12] А.В. Ненашев, А.В. Двуреченский, ЖЭТФ, 118 (3), 570 (2000). http://www.jetp.ac.ru/cgi-bin/index/r/118/3/p570?a=list [Пер. версия: 10.1134/1.1320083].

[13] Е.М. Труханов, С.А. Тийс, Письма в ЖТФ, 45 (22), 28 (2019). DOI: 10.21883/PJTF.2019.22.48645.17893 [Пер. версия: 10.1134/S1063785019110282].

[14] J.E. Smith, Jr., M.H. Brodsky, B.I. Crowder, M.I. Nathan, Phys. Rev. Lett., 26, 642 (1971). DOI: 10.1103/PhysRevLett.26.642

[15] M. Wihl, M. Cardona, J. Tauc, J. Non-Cryst. Solids, 8-10, 172 (1972). DOI: 10.1016/0022-3093(72)90132-9

[16] A.V. Kolobov, J. Appl. Phys., 87, 2926 (2000). DOI: $10.1063 / 1.372279$

[17] D.M. Zhigunov, G.N. Kamaev, P.K. Kashkarov, V.A. Volodin, Appl. Phys. Lett., 113, 023101 (2018). DOI: $10.1063 / 1.5037008$

[18] M.H. Brodsky, M. Cardona, J.J. Cuomo, Phys. Rev. B., 16, 3556 (1977). DOI: 10.1103/PhysRevB.16.3556

[19] V.A. Volodin, D.I. Koshelev, J. Raman Spectr., 44, 1760 (2013). DOI: $10.1002 / j$ rs.4408

[20] K.W. Jobson, J.-P.R. Wells, R.E.I. Schropp, D.A. Carder, P.J. Phillips, J.I. Dijkhuis, Phys. Rev. B, 73, 155202 (2006). DOI: 10.1103/PhysRevB.73.155202 